\title{
Cuerpo, vida, subjetividad y verdad: parrhesía y bíos en el cinismo. Implicaciones para la educación y la educación corporal
}

\section{Santiago Pich*}

\section{Resumen}

Este artículo trata del problema del par conceptual parrhesía-bíos, que es central en el último dominio de la obra de Michel Foucault. Se detiene, en particular, en el modo de elaboración de ese par conceptual en la interpretación del cinismo hecha por el pensador galo. En ese contexto, se pregunta por el lugar del cuerpo en la producción del logos, y los desplazamientos en la relación entre el cuerpo y la palabra, entre el bíos philosophikós y el bíos kynikós. Problematiza, con base a esas elaboraciones, posibles implicaciones para pensar la educación y la educación corporal.

\section{Palabras clave}

Michel Foucault, cuerpo, cínicos, bíos kynikós, parrhesía cínica.

Recepción original: 24 de abril de 2019

Aceptación: 12 de septiembre de 2019

Publicación: 20 de enero de 2020

\section{Introducción}

Las obras de Michel Foucault se han vuelto una referencia importante para el campo académico de la educación. Su original arqueología del saber y su analítica del poder (su genealogía del poder) fueron y continúan siendo horizontes teóricos de gran potencial para un análisis con nuevos lentes de cómo el sistema de enseñanza moderno opera, sea por la vía del análisis de los discursos o por el modo de funcionamiento del poder en las instituciones educacionales, con énfasis para el sistema formal de enseñanza. A pesar de las originales miradas que esos ejes investigativos suponen, han sido ampliamente criticados por la fuerza que adquiere en ellos la dimensión estructural del análisis, siendo difícil vislumbrar horizontes de posibilidad para nuevas construcciones epistemológicas en el campo de la formación humana. A pesar de las reiteradas oportunidades en las cuales el pensador galo rechaza la crítica sobre el carácter estructural de su obra, es adecuado apuntar, en particular sobre el problema del cuerpo, que en su analítica del poder, principalmente aquella elaborada en la primera mitad de la década de los setenta del siglo xx y que tiene a la obra Vigilar y castigar (Foucault, 2002a) como su principal referencia, el cuerpo (y el sujeto) es una instancia que es solamente el blanco del poder, sin que haya ele-

$\left(^{*}\right)$ Profesor de Educación Física (IPEF/Argentina), Magister en Ciencia del Movimiento Humano (UFSM/Brasil) y Doctor en Ciencias Humanas (PPGICH/Brasil). Profesor del Departamento de Estudios Especializados en Educación (EED) y del Programa de Post-grado en Ciencias de la Educación - maestría y doctorado - (PPGE) de la Universidad Federal de Santa Catarina (UFSC). Dirección electrónica: santiago.pich@yahoo.com.br 
mentos que nos permitan identificar brechas o líneas de fuga para resistencias posibles. El poder sobre el cuerpo y sobre la vida, adquieren así una forma unidireccional, descuidando al cuerpo vivido (ver Ortega, 2008). Por otro lado, los análisis de la formación humana en el sistema de enseñanza elaborados con referencia a esa analítica del poder, adquieren un carácter negativo, porque la relación entre el profesor y el alumno estaría enmarcada en la lógica institucional de la escuela y, por ende, en el plano del poder disciplinar. Quedando así, el cuerpo y la educación (escolar) relegados siempre a la esfera de la formación de cuerpos disciplinados: sujetos dóciles y obedientes políticamente y productivos económicamente.

En la segunda mitad de esa década de 1970, Foucault opera un desplazamiento y elabora el concepto de gubernamentalidad, para indicar que el poder es siempre relacional y que para que la dominación sea posible es necesario que el sujeto que se encuentra en situación de supremacía en la relación de poder ejerza, principalmente, la dirección de la conciencia de aquellos que se sitúan en la condición de subalternos. Esa condición hace que gobernar sea entendido como el arte de conducir la conducta. La mencionada categoría, la gubernamentalidad, es elaborada y presentada en el curso «Seguridad, Territorio y Población», dictado en el año lectivo 1977-1978. En ese momento la pedagogía y la relación profesor-alumno se perfila como una de las expresiones del gobierno de los hombres (Foucault, 2006). Para Michel Senellart (2011):

La invención del concepto de «gubernamentalidad» procede a la vez del desarrollo de un plan preestablecido (...) y de un pensamiento en movimiento que decide, a partir de sus descubrimientos, reactivar ciertos análisis anteriores (a propósito del arte de gobernar y la pastoral de las almas), en una perspectiva teórica ampliada. (Senellart, 2011, p. 437)

En ese movimiento teórico Foucault se vale del análisis del poder pastoral cristiano para situarlo como paradigma de la emergencia, en la modernidad, de la tecnología de poder que hace posible una relación de poder que implique al sujeto en su condición de sujeción, pero que, como tal, está siempre siendo, precisa siempre ser renovada, lo que deja margen para identificar posibles líneas de fuga, lo que es llamado por Foucault con el neologismo de contra-conductas. Es oportuno señalar también que en ese momento de la obra también emerge, como objeto de la analítica de poder foucaultiana, la biopolítica como forma de regulación de la vida de la población, que pasa a formar un binomio con el concepto de gubernamentalidad.

En el tercer momento o dominio de la obra del autor galo (Deleuze, 1995) vemos un desplazamiento de la postura con relación a la constitución de la subjetividad, que permite la apertura para pensar la vida humana como una obra de arte y que crea nuevas posibilidades para concebir la relación entre el cuerpo, el sujeto, la verdad y el poder. Ese período de la producción foucaultiana abarca los volúmenes 2 y 3 de la Historia de la Sexualidad, el mayor proyecto teórico del pensador francés, los cursos dictados por Foucault en el Collège de France en la década de 80: desde «El Gobierno de los Vivos» (1979-1980), pasando por «Subjetividad y Verdad» (19801981), «La Hermenéutica del Sujeto» (1981-1982), concluyendo con «El Gobierno de sí y de los otros l» (1982-1983) y «El Gobierno de sí y de los otros II: el coraje de la verdad» (1983-1984), además de las diversas entrevistas y conferencias dictadas entre el final de la década de 1970 hasta 1984, año de su fallecimiento, que fueron 
publicadas en los Dits et écrits. También forman parte de este corpus los cursos dictados por Foucault fuera de Francia, particularmente en la Universidad de Lovaina (1981) sobre la función de la confesión en el juicio, en la Universidad de Dartmouth (1980) sobre el origen de la hermenéutica de sí y en la Universidad de Berkeley (1983) sobre las nociones de subjetividad y de parrhesía en la antigüedad griega clásica y en el helenismo.

Es notable observar que Foucault simplemente abandona el proyecto que emprendiera sobre la genealogía del poder de la década de 1970 y que tiene en los conceptos de biopoder, biopolítica, poder disciplinar y gubernamentalidad a sus categorías fundantes. Después del curso de 1978-1979 «Nacimiento de la biopolítica», esa temática no es evocada posteriormente. Sin embargo, eso no quiere decir que el problema de la relación con la vida, con el poder o con la gubernamentalidad y la veridicción fuera dejado de lado, sino que al realizar un desplazamiento espacial y temporal de sus terrenos de excavación, retrotrayendo el tiempo a la antigüedad clásica griega y al helenismo griego y romano le permiten al pensador galo elaborar la producción de la subjetividad en términos totalmente nuevos.

Entendemos que uno de los movimientos que realiza es una actualización del lugar ontológico del cuerpo en la constitución de la subjetividad, además entiende que la constitución de la subjetividad es algo permanentemente abierto, en constante devenir, por tanto la relación del sujeto de sí para consigo implica una práctica permanente de «sí», que tiene su centro en la constitución del sujeto ético a través de una «estilización de la existencia» (Foucault, 2003). La dualidad constitutiva del sujeto, el cuerpo y el alma, no es vista como formada por substancias antagónicas, sino por dimensiones que guardan relaciones de mutua implicación y que, dependiendo de las escuelas analizadas, adquiere una configuración particular. Tal proceso de autocreación tiene como uno de sus pilares centrales a la relación del «mestre» con el discípulo, siendo, por tanto, la dimensión «psicagógica» constitutiva de ese proceso ${ }^{1}$. Así, la relación entre los sujetos no se da como como la sujeción del individuo a la intervención del poder sobre el cuerpo individual, sino como la relación necesaria para que una nueva relación del sujeto con la verdad de sí sea posible. Sin embargo, eso solo es posible en contextos estructurales que tengan a ese ideal formativo como un pilar constitutivo, no siendo un movimiento individual. En ese desplazamiento son centrales los conceptos de bíos y parrhesía, nociones a partir de las cuales nos proponemos pensar implicaciones posibles para el campo de la formación humana y la educación corporal, con énfasis para la elaboración cínica de las mismas.

\section{Notas sobre la genealogía de la moral}

La genealogía emprendida por el pensador francés en sus últimos años de vida, que tiene al problema del sujeto ético como su eje, nos abre un fértil horizonte para

(1) Foucault se ocupa de diferenciar pedagogía de psicagogia. La primera se caracteriza por la relación entre quien enseña y quien aprende pautada por la mediación de contenidos cognitivos a ser apropiados y, la segunda, por una relación de compromiso ético entre quien orienta la formación, el Mestre y la palabra que enuncia, dirigida a quien es orientado, el discípulo, y está centrada en la transformación del alma del segundo, la transformación de su ser de sujeto orientada por el ideal de la excelencia y la ejemplaridad. 
situar el complejo problema de la relación entre el sujeto y la verdad, o mejor, la tríada: el sujeto (o mejor el «sí», como el autor mismo prefería, o la subjetividad), la verdad o la veridicción y el poder o las formas de gobierno (en este caso de sí).

Entendemos, siguiendo la interpretación de Judith Butler (2008), que tal movimiento teórico-metodológico encuentra sus raíces hacia fines de la década de 70 del siglo $x x$, en particular en el momento en el que Foucault elabora el concepto de crítica. En 1978 dicta una conferencia intitulada «¿Qué es la crítica?», en la cual centra su atención en el problema de los límites del gobierno y, principalmente, en la manera cómo los gobernados son implicados y se implican en la pregunta sobre los modos y los límites del gobierno (Foucault, 1995). Esa idea -la importancia del concepto de crítica en los años 80- puede ser corroborada en las palabras del propio autor, en uno de los últimos seminarios que impartió, en 1983, en la Universidad de Berkeley y que tenía por objeto al problema de la parrhesía, categoría de crucial importancia para el trabajo desarrollado por Foucault en los años 80 del siglo xx (y para el presente texto). En el cierre del seminario afirmó que el objetivo del mismo era «construir una genealogía de la actividad crítica en la filosofía occidental» (Foucault, 2004a - cursiva nuestra). Para Butler (2008) es crucial diferenciar la perspectiva foucaultiana de la crítica que está emparentada con la ética, del juicio que se relaciona con el criticismo, siendo que el proyecto de Foucault no debe, en ninguna hipótesis, ser asociado con el segundo. En las palabras de la autora:

\footnotetext{
El juicio, para ambos pensadores [Theodor Adorno y Raymond Williams], es una manera de subsumir lo particular en una categoría general ya constituida, mientras que la crítica interroga sobre la constitución oclusiva del campo de conocimiento al que pertenecen esas mismas categorías. Pensar el problema de la libertad, y el de la ética en general, más allá del juicio, es especialmente importante para Foucault: el pensamiento crítico consistiría justamente en ese empeño. (Butler 2008, p. 143)
}

Es importante señalar que Foucault elabora ese problema en el mismo momento en el que está desarrollando un cierre de su análisis de objetos situados en la modernidad, período histórico en el cual él no verá posibilidades más que marginales para la constitución del sujeto ético. En ese contexto, entendemos que se sitúa la tipología de las sociedades que es presentada en el segundo volumen de la Historia de la sexualidad. 2. El uso de los placeres. Para el autor galo, en la tradición occidental han existido dos tipos de sociedades: unas a las que él llama «sociedades de código» y otras denominadas de «sociedades de ética». Las primeras se caracterizan por contar con un código moral altamente prescriptivo, detallado y minucioso y con instituciones sociales con gran poder de coerción y control que operan como instituidoras de los códigos. En tales formaciones sociales la relación con la norma moral es claramente heteronormativa, caracterizándose por un modo de subjetivación pautado en la lógica de la sujeción. Un elemento que se desprende del postulado anterior es que la experiencia de la libertad y la idea de autonomía y de ética, resulta claramente obturada en tales condiciones. En ese contexto, Foucault inscribe a las sociedades occidentales modernas y al cristianismo monástico, donde las posibilidades de producción de la subjetividad fuera de los códigos y de los modelos identitarios que ellas presuponen son escasas. Las segundas se caracterizan por contar con un marco normativo más abierto, menos detallado, constituyéndose más en tratados sobre la existencia (el bíos), que en normas prescriptas a ser seguidas (Foucault, 2002b). Además, en las sociedades de ética la relación de los sujetos con las 
normas gana la forma de una estilización de los códigos morales, lo que significa, siguiendo a Butler (2008), una relación poiética con la normatividad social. En tales formaciones sociales, el foco está puesto en la producción del sujeto ético, entendido como aquel que hace una experiencia reflexiva de la libertad (Foucault, 2004b).

Para evitar equívocos en la interpretación de la obra, es fundamental también tener presente que en el mismo texto al que nos referimos en el inicio de este tópico, Foucault avanza en la elaboración de su concepto de filosofía y entendemos que ésa es la segunda clave de lectura a partir de la cual es posible comprender el giro dado en la década siguiente. Entiende que en la modernidad fueron desarrollados dos conceptos de filosofía por uno de los padres fundadores del pensamiento moderno, el filósofo prusiano Immanuel Kant. Por un lado, un concepto de filosofía que se funda en la teoría del conocimiento y tiene a los procesos formales de verificación de la verdad de una proposición o de un enunciado como su horizonte metodológico y a la epistemología como su dominio privilegiado de saber. En ese contexto, las críticas kantianas son fundamentales, siendo la Crítica de la Razón pura (1781) la obra que por excelencia funda esa corriente. Por otro lado, se encuentra otra tradición que tiene como su principal referencia teórica al texto «¿Qué es la ilustración?» [«¿Was ist Aufklärung?»] (1784). La interpretación foucaultiana se orienta en el sentido de que en ese texto Kant abrió la pregunta sobre qué es el presente que se vive, así como también sobre cómo acontece la relación del sujeto que practica la actitud crítica con ese presente en el que vive. Esta cuestión es denominada por Foucault como la pregunta fundadora de la tradición crítica y tiene en la actitud crítica a su modo de ser. Ese concepto de filosofía toma distancia respecto a una relación formal con el saber, implicando a quien practica la filosofía en la pregunta que formula, no pudiendo ésta ser reducida a una actividad instrumental. En esa tradición están inscritos autores como Max Weber, los pensadores de la Escuela de Frankfurt y él mismo se reconoce en ella (Foucault, 1995). Por tanto, hacer filosofía para Foucault es siempre una «ontología del presente». Por ese motivo, no puede ser comprendido su recurso al helenismo como una fuga del presente, sino, tal vez, como una excavación que se hace a partir de la pregunta sobre el presente y sus (im)posibilidades. Además, el recurso a la Grecia clásica y principalmente al helenismo es una forma de actualizar la pregunta sobre la implicación del sujeto en la verdad que enuncia, por ser la filosofía, en ese contexto, un modo de estilización de la existencia y ese parece ser un elemento fundamental para la crítica realizada por Foucault al modo en que se presenta el concepto hegemónico de filosofía en la modernidad y, particularmente, en la Francia de los años 60, 70 y 80 del siglo XX.

En ese sentido, observa Foucault un radical cambio en la modernidad en la relación del sujeto con la verdad, que podemos llamar de «desespiritualización», porque se realiza una quiebra en la implicación entre quien enuncia la verdad y la verdad que es enunciada. Para el autor:

Tal como es en lo sucesivo, la verdad no es capaz de salvar al sujeto. Si se define la espiritualidad como la forma de prácticas que postulan que, tal como es, el sujeto no es capaz de verdad pero que ésta, tal como es, es capaz de transfigurarlo y salvarlo, diremos que la edad moderna de las relaciones entre sujeto y verdad comienza el día en que postulamos que, tal como es, el sujeto es capaz de verdad pero que ésta, tal como es, no es capaz de salvarlo. (Foucault, 2006, p. 38)

Otra herramienta teórica de gran valor en el pensamiento foucaultiano es el concepto de «cuidado de sí» que está estrechamente vinculado al de áskesis o ascesis. 
Cuidar de sí, idea que Foucault recupera de los griegos (de la era clásica) y del helenismo griego y romano, era en primer lugar una práctica que debía ser realizada a lo largo de toda la vida, y cumplía un papel de ley ética, de compromiso del sujeto para consigo orientada por la transformación de sí y dada en la enunciación y práctica de la verdad de sí. Además, esa relación nunca era individual, sino siempre mediada por la figura del «mestre», con el cual el sujeto debía mantener una relación de escucha, de veracidad y de amorosidad. Ese vínculo presuponía el «hablar franco", un hablar que coloca en riesgo y compromete al sujeto de la enunciación con la verdad enunciada, la parrhesía y tenía como forma modelo de expresión al diálogo socrático. Así:

(...) la cuestión que plantean los griegos y los romanos, creo, acerca de las relaciones entre sujeto y práctica consiste en saber en qué medida el hecho de conocer la verdad, decir la verdad, practicar y ejercer la verdad, puede permitir al sujeto no sólo actuar como debe hacerlo sino ser como debe ser y quiere ser. (Foucault, 2006, p. 305)

Esa práctica es de carácter «ethopoiético», e implica, por tanto, la creación ética de sí, una estética de la existencia, vivir la propia vida como obra de arte. Esa relación con la verdad permite al sujeto (o al «sí») la «constitución de un saber sobre el mundo como experiencia espiritual del sujeto» (Ibid.). El concepto de cuidado de sí se vincula directamente a la idea de ascesis, que tenía como objeto «la formación de cierta relación de sí consigo que fuera plena, consumada, completa, autosuficiente y susceptible de producir esa transfiguración de sí que es la felicidad que uno conquista consigo mismo» (Foucault, 2006, p. 306). Además, la ascesis, en este caso, difiere de la ascesis intramundana que caracteriza al cristianismo (principalmente al de corte puritano), por no ser una búsqueda orientada a la renuncia de algo que se posee (la esencia divina), sino la búsqueda de dotarse de algo que no se tiene, un complementarse a sí mismo, a partir de una relación de sí para consigo orientada a la transformación de sí.

Así, vemos preliminarmente que el problema de la educación en el tercer momento foucaultiano se presenta como un terreno fértil para tener un acceso a otro concepto de subjetividad, por la relación activa para con él que el sujeto debe guardar para consigo, bien como para una relación pedagógica no centrada en un objeto cognoscible que tiene como mediador al profesor, sino como una relación de compromiso y veracidad entre los interlocutores que tiene como objeto la enunciación y la práctica de la verdad de sí. En ese contexto, la noción de bíos es de capital importancia.

\section{Apuntes sobre la noción de bíos}

Una diferencia importante es la que nuestro autor realiza entre las técnicas de existencia, técnicas para vivir (tékhnai perí ton bíon) y las reglas de conducta. En cuanto las primeras están constituidas por un conjunto de preceptos un tanto generales para producir la existencia, pero sin una codificación exhaustiva, las segundas son conformadas por una meticulosa ordenación normativa que regula la conducta de la vida de los individuos. Además, las tékhnai son concebidas como un conjunto sistemático de acciones y un determinado modo de acción, que tienen como objeto dar forma a la vida que se vive, pero no un carácter prescriptivo sobre tal forma. (Foucault, 2016). 
La dificultad para tener herramientas de comprensión del bíos griego reside para nosotros modernos, según Foucault, en tres elementos: 1) porque estamos atravesados por la lógica cristiana en la cual la vida es escindida en dos dimensiones, siendo la fundamental la vida del alma que tiende a la transcendencia, en cuanto el bíos es de carácter inmanente (este parece ser una apuesta por la radicalidad de la inmanencia y de la contingencia); 2) además el bíos no se define por una dimensión de corte social, como la profesión o el status, sino que se vincula con un modo singular de producción de la existencia, siendo que singular aquí no significa solipsista, sino un modo ejemplar de inscripción de la vida que se vive en la sociedad de la cual se hace parte; y 3) tampoco es algo que pueda ser definido biológicamente (Ibid). Veamos entonces la definición dada a ese concepto:

Es la forma de relación que él mismo (el individuo) decide tener con las cosas, la manera como se pone en relación con relación a ellas, la manera como las finaliza con relación a sí mismo. Es además la manera como inserta su propia libertad, sus propios fines, su propio proyecto en las cosas en sí, la manera como, por decirlo así, las pone en perspectiva y las utiliza. (Foucault, 2016, p. 22)

Vemos en la citación anterior que el foco es puesto en el juego que el individuo realiza a partir de su relación singular con la sociedad, no un mero movimiento de aislamiento y renuncia individual. El bíos se realiza en la pólis o en el contexto de la sociedad política en el helenismo griego y romano, no fuera de ella. A pesar de encontrar paralelos entre esa idea y la noción de subjetividad moderna, en rigor no es posible encontrar un concepto equivalente al de subjetividad en el universo cultural griego. Sin embargo, a falta de un término equivalente se podría decir que el bíos es la subjetividad entre los griegos. Nuestro autor señala que las tékhnai perí ton bíon implican insertar la subjetividad, el bíos en el interior de un código. Evidentemente, subjetividad entendida como la producción de una estilización de la existencia, noción que será de fundamental importancia para los trabajos foucaultianos de los años 80 del siglo XX.

Al contrario, lo que caracteriza a las sociedades occidentales modernas es un concepto de subjetividad en cuanto una herencia cristiana secularizada, un modelo identitario claramente codificado e institucionalmente producido. En esa dirección, vale la pena diferenciar la producción de la subjetividad en la tradición cristiana del bíos griego. Son tres puntos que nos permiten realizar esa demarcación: 1) En cuanto a la tradición griega la subjetividad presupone una finalidad que cada uno define para sí mismo, en el cristianismo existe un fin común y absoluto; 2) en la tradición griega se establece un trabajo continuo de sí para consigo mismo para posibilitar el venir-a-ser de la subjetividad sin una referencia identitaria que opere como modelo, en la tradición cristiana el foco está puesto en la conversión de los sujetos que tienen como modelo identitario a la vida de Cristo; y 3) el bíos griego implica una busca indefinida y al mismo tiempo finita de dar forma a la existencia, que al mismo tiempo se alcanza y no se alcanza, porque nunca se llega definitivamente a ella; por su parte la subjetividad cristiana tiene como horizonte la autenticidad, el descubrimiento de una esencia. Así el problema del bíos ${ }^{2}$ no puede ser

(2) Es importante señalar que es una constante en Foucault mantener algunas categorías en su lengua original, por entender que ellas condensan un modo singular de decir el mundo, de instituirlo. Así también sucede, por ejemplo, con la noción aphrodisia en el volumen segundo de la Historia de la 
situado como una salida individual para un contexto social dado, sino que debe ser concebido, así entendemos, como un proyecto formativo a escala societaria, o por lo menos de algunas instituciones que forman parte de ella.

\section{La parrhesía y la verdad des-velada de sí y del otro y el bíos kynikós}

Foucault planteará la parrhesía ante todo como un concepto político, tema que se volvió un eje articulador de las relaciones entre el poder, el sujeto y la verdad. La empresa que aborda entrelaza tres elementos con sus complejas relaciones: el saber, como práctica de veridicción, el poder no como algo sustancial sino como lo que gobierna la vida de los hombres y los modos de constitución del sujeto, a partir de las prácticas de sí (Foucault, 2010). Sin embargo, ese movimiento no puede ser tomado de manera monolítica, suponiendo que el concepto de parrhesía guarda unidad interna. Ese cuidado es relevante porque entendemos, siguiendo el análisis realizado por Gros (2014) acerca del concepto de parrhesía que es un vector de los tres últimos cursos dictados por Foucault: «La Hermenéutica del Sujeto» (1982), «El gobierno de sí y de los otros |» (1983), y «El gobierno de sí y de los otros II: el Coraje de la Verdad» (1984) ${ }^{3}$. Así, de acuerdo con la manera en que esa articulación se operó históricamente, resultan modos diversos de realización de la parrhesía. Recordamos que es objeto de discusión en el presente artículo los desplazamientos del concepto, teniendo como eje el lugar del cuerpo en la producción del decir verdadero, del decir franco, presentes en el último modo de expresión de la parrhesía elaborado por Foucault, la cínica.

Se trata de decir la verdad, de decirla de forma potente y de manera arriesgada, en ese caso, la relación entre el parresiastes y su interlocutor corre riesgo y se trata de tener coraje de decir, de bien decir. «Para decirlo en dos palabras, la parrhesía es, por ende, el coraje de la verdad en quien habla y asume el riesgo de decir, a pesar de todo, toda la verdad que concibe, pero es también el coraje del interlocutor que acepta recibir como cierta la verdad ofensiva que escucha» (Foucault, 2010, p. 52). En el registro parresiástico la relación del sujeto con la verdad está signada por el riesgo que presupone asumirla y enunciarla por un doble motivo: porque la enunciación, en la medida que es acto ethopoiético, por tanto de constitución de sí del sujeto ético, no puede implicar la disociación entre lo enunciado y el enunciador, sino, por el contrario, su mutua implicación. Por otro lado, la enunciación, en la medida que está dirigida al Otro, (y dirigida al Otro nunca en el sentido de la adulación), implica también asumir el riesgo por las consecuencias de lo que dice que pueden ir desde perder la amistad hasta poner en juego la propia vida (como es el caso de Sócrates). Eso resulta porque se trata de decir todo lo que se considere necesario para la constitución ética del sujeto a quien el discurso se dirige, sea porque este tiene como deber gobernar primero a sí para poder gobernar a los otros, o por ser

sexualidad. 2. El uso de los placeres. Eso se debe a la idea de que los conceptos enuncian realidades, no cumplen una función representacional.

(3) Resulta importante señalar, a pesar de que no es referido por Gros, que el curso dictado por Foucault en Berkeley en 1983, llamado «Discurso y verdad en la antigua Grecia» está centrado en la noción de parrhesía. 
el discípulo de un maestro o alguien a quien se dirige un consejo. También es elemento importante la forma de decir, es importante evitar el equívoco de pensar que ella presupone "decirlo todo», en sentido de que después de lo que se dice no habría nada más a decir, sino que se trata de «ponerlo todo en el decir» (Gabilondo y Megías, 2004, p. 24). Por otra parte, ella presupone una actitud de abertura al Otro por parte de quien escucha, la escucha es condición de la parrhesía, porque la palabra recibida, al no ser nunca adulación, retórica o pedagogía (Foucault, 2004a), tiende a herir, a ser, como podría ser dicho con referencia al psicoanálisis, anti-narcicística. La parrhesía, a pesar de ser una forma de relación consigo y con el otro pautada por la una actitud moral, no se resume a ella. Sino que es también tékhnai, formas codificadas de acción que tornan posible el devenir del sujeto ético. Las tékhnai no son códigos morales que deben ser obedecidos, sino que son herramientas que el sujeto puede disponer para poder establecer una relación ética. Es conocida la crítica hecha a Foucault sobre la supuesta reclusión en la individualidad ética en los estudios de los años 80 . Sin embargo, entendemos que el proyecto va justamente en la dirección contraria, elaborando herramientas potentes para problematizar la política del presente, a partir de la crítica a la desconexión entre el sujeto ético y la política. Consideramos oportuno el apuntamiento hecho por Gabilondo y Megías (2004) sobre la relación entre ética y política, teniendo al concepto de parrhesía como mediador, o dicho de otro modo, la parrhesía es entendida como la bisagra entre la ética y la política, como ese «entre lugar», entre la política y la ética y es, justamente, la parrhesía cínica la que alcanza la más alta expresión en ese sentido.

El parresiastes, aquel que conduce la parrhesía, es caracterizado como el que pone en relación el logos con el bíos (Foucault, 2004a, p. 143), aquel que revela una problematización del logos a partir de la verdad del bíos, de su propia existencia, la vida es el lugar en el que la verdad encuentra su anclaje. La vida ejemplar es la dimensión en dónde el logos encuentra su horizonte de realización. A partir de esa condición le es dado al parresiastes la conducción del proceso que lleva al otro a la transformación de su vida, a la transformación del sujeto en su ser de sujeto (Foucault, 2006). Por ese motivo la relación parresiástica es siempre una relación formativa, en la cual el Mestre o parresiastes y el discípulo, o el interlocutor del primero, se implican en una relación centrada en el compromiso ético del decir franco y la escucha atenta y abierta. Sin embargo, es relevante considerar que la relación entre bíos y logos no es unívoca, dado que hay diferentes elaboraciones de la parrhesía y en cada una de ellas esa relación adquiere un carácter singular. Foucault (2004a) presenta cinco tipos de parrhesía: la política (que caracteriza a la pólis ateniense), la ética o filosófico-socrática, y tres formas de parrhesía en el helenismo: la parrhesía como vida de comunidad en el epicureísmo, como vida pública que caracteriza a la parrhesía cínica y como aspecto de las relaciones personales, forma ideal-típica del estoicismo. A pesar de esa caracterización ideal-típica, es necesario indicar que existen cruzamientos e hibridaciones entre ellas.

Sobre los diferentes tipos de parrhesía a los cuales Foucault se refiere, haremos hincapié en la relación entre dos tipos de parrhesía: la ética y la cínica. En el caso de la parrhesía ética o filosófica, cuyo representante paradigmático es Sócrates vemos un desplazamiento que nos interesa para el desarrollo de nuestro trabajo: la relación cuerpo-alma y el lugar del bíos en ese modo de expresión parresiástico. Es en el 
bíos, como estilística de la existencia que se funda ese nuevo modo de parrhesía y no en el alma, como elemento divino que constituye al sujeto. Ese movimiento, que se realiza a partir de un cambio de referenciales que van del Alcibíades al Laques, redunda en una apuesta cada vez más clara en dirección a la corporalidad y a la inmanencia, en la medida en que la relación entre cuerpo y alma comienza a ser concebida en otros términos, otorgando al cuerpo el lugar e instancia ontológica de constitución del sujeto. Para Gros:

En él (en el Laques), el cuidado de sí no consiste en el conocimiento del alma como parte divina de sí mismo, sino que el objeto del cuidado es el bios, la vida, la existencia, y cuidarse de sí significará dar forma a la propia existencia, someter la propia vida a reglas, a una técnica, ponerla a prueba según ciertos procedimientos: es la filosofía como arte de la vida, técnica de existencia, estética de sí. El Laques habla de este coraje y de este riesgo: no el de situar más allá del cuerpo una realidad ontológica distinta (el alma), sino el de saber lo que le cuesta al que quiere dar a su vida inmanente cierto estilo metódico. (Gros, 2014, p. 136)

Aquí (en la parrhesía ética) el cuidado de sí ya no consiste más en el conocimiento del alma como parte divina en sí misma, sino que el objeto del cuidado pasa a ser el bíos, la vida, la existencia y cuidar de sí significará dar forma a la propia existencia, someter la propia vida a reglas, a una técnica, a ponerla a prueba según determinados procedimientos: es la filosofía como arte de la vida, técnica de existencia, estética de sí. El Laques habla de ese coraje y de ese riesgo: el de no situar más allá del propio cuerpo una realidad ontológica distinta (el alma), sino de saber cuánto le cuesta a aquel que quiere dar a su vida inmanente un cierto estilo reglado (Gros, 2014, pp. 161-162).

Las palabras citadas resumen elocuentemente el desplazamiento al que nos referíamos, el cuerpo gana un nuevo lugar en la constitución del sujeto en dirección al plano inmanente, al plano de la vida. Sin embargo, ese movimiento, que tiene en la obra platónico-socrática Laques su lugar de sistematización, todavía no alcanza a tener la radicalidad que cobra en el cinismo, a pesar de ser una bisagra entre el bíos philosophikos, típico del platonismo-epicureísmo-estoicismo y representado ejemplarmente en el Alcibíades, y el bíos kynikós, del cinismo (cf. Foucault, 2010; Gros, 2011, 2014).

En ese sentido, vale la pena recordar la relación ambivalente que mantenían los cínicos, en particular Diógenes y Crates, con la figura de Sócrates. Al mismo tiempo en que era reconocido como un sujeto que asumió la tarea de cuidar de sí y de los otros, a partir de comprometerse con la verdad que enunciaba, y también respondió por los riesgos por ese decir veraz hasta la muerte, literalmente; no es menos verdad que el padre de la filosofía vivió una vida adecuada a las normas de la pólis, puesto que se casó, tuvo hijos y una casa. De alguna manera, Sócrates no hizo explotar en su cuerpo la verdad como escándalo, que es un eje vertebrador de la parrhesía cínica, del bíos kynikós.

\section{Cinismo: parrhesía y bíos; cuerpo, palabra y verdad...}

La especificidad del cinismo con relación a las demás escuelas del helenismo que fueron analizadas por Foucault reside en su carácter de no ser una escuela de letrados, elemento que era distintivo del epicureísmo y del estoicismo, lo que les daba una posición elitizada en el contexto de la época. La resistencia cínica al registro 
escrito de su doctrina, además de hacerlo llegar a círculos sociales más amplios que el de las clases privilegiadas de Grecia y Roma, le atribuye un carácter de primacía a la práctica del modo de vida cínico con relación a la doctrina. Elemento que es analizado como opuesto en las otras dos escuelas mencionadas, ya que de los cínicos se conserva una gran cantidad de relatos de sus vidas, y de las otras escuelas estudiadas por Foucault (el epicureísmo y el estoicismo) se ha conservado un gran legado doctrinario. Tal vez sea ese uno de los motivos del encantamiento de Foucault por el cinismo en el último curso dictado en el Collège de France. Además, los relatos sobre los cínicos muestran su predilección por los espacios públicos para la discusión, a los cuales diferentes individuos tenían acceso libremente y no por las escuelas filosóficas cerradas e institucionalizadas, que además de la exigencia de la lectoescritura, demandaban un pago por parte de los participantes. Ese habría sido el motivo de la mayor popularidad de los cínicos entre diferentes niveles sociales, inclusive entre los primeros cristianos. Los registros a los cuales es posible acceder presentan un gran conjunto de relatos de cómo era el modo de vida cínico, para los cuales la propia vida se «con-funde» con la filosofía que se profesa, motivo por el cual el cuerpo adquiere un rol central en esa corriente de pensamiento (Foucault, 2004a, pp. 152-153). También es digno de nota el hecho que el pensador galo se preocupa con situar claramente a los cínicos como una escuela genuinamente griega, a pesar de las ilaciones hechas con relación a las influencias orientales de las que se habría nutrido, en particular de las provenientes de India. El elemento helénico del cinismo es la centralidad que adquiere para esa escuela la relación con la verdad, como veremos más adelante. Por ese motivo, de ellos se conservan relatos de vidas ejemplares, entre las cuales se destaca la de Diógenes como una figura heroica que llevó una vida ejemplar (Foucault, 2004, p. 157). Conviene recordar que la ejemplaridad en el contexto griego era la puerta de acceso a la inmortalidad, dado que quien conseguía vivir de manera virtuosa tendría su nombre y su existencia inmortalizados en la memoria de los ciudadanos. Ejemplaridad y virtuosismo no significan en ese contexto emular la vida o los valores vividos por otro, como será característico en la tradición cristiana, sino producir la propia existencia como una obra de arte. Lo que podría ser emulado no sería el contenido de la existencia, sino el modo de relación con la vida regido por la virtuosidad, y diríamos en el registro foucaultiano, por el coraje de la verdad.

La relación con la verdad que caracteriza a la parrhesía cínica merece un capítulo especial, como preámbulo para avanzar posteriormente en la dimensión del lugar del cuerpo en la relación parresiástica. En la analítica foucaultiana tres elementos caracterizan a esta expresión de la parrhesía: 1) la prédica crítica, 2) la conducta escandalosa, y 3) el diálogo provocativo (Foucault, 2004a, p. 157). La prédica crítica presupone la crítica hecha en espacios públicos no elitizados, sino abierto a las masas y dirigida contra la arbitrariedad de las normas sociales y las instituciones que las transmiten, porque limitan y/o impiden la libertad y la independencia. La conducta escandalosa pone en tela de juicio hábitos colectivos, normas sociales, reglas institucionales, normas de decencia, etc. y tiene como procedimientos a la inversión de papeles, la transposición de una regla de un dominio a otro y unir dos reglas aparentemente contradictorias. El primer caso puede ser ejemplificado con la demostración dada por Diógenes a Alejandro Magno sobre el verdadero soberano, que era aquel que ejerce la soberanía sobre sí mismo y no sobre vastos territorios. 
El segundo procedimiento encuentra un ejemplo en la autocoronación de Diógenes en los Juegos Ístmicos por haber vencido a los vicios, a la pobreza y a la hipocresía de las normas sociales, lo que era mucho más significativo que el entrenamiento corporal para vencer una prueba atlética. Por fin, el tercer procedimiento puede ser ilustrado con la puesta en relación de las diversas necesidades corporales. Los relatos sobre la vida de los cínicos dan cuenta que para demostrar la arbitrariedad y superficialidad de las normas sociales tanto comían como se masturbaban y copulaban en espacios públicos, con el fin de cuestionar los motivos que llevaban a permitir el carácter público de la alimentación y el carácter privado de la satisfacción de las necesidades de carácter sexual, ambas del orden de la naturaleza.

El tercer elemento que caracteriza a la parrhesía cínica es el diálogo provocativo. En este caso los cínicos se diferencian de Sócrates por la inversión de roles en el acontecer del diálogo. En el diálogo socrático el parresiastés (Sócrates) se sitúa en el lugar del que aparenta no saber para que, a través de las preguntas que realiza, el sujeto interpelado tome conciencia de que nada sabe sobre lo que cree saber. En el diálogo cínico el interpelado es el que hace las preguntas (como lo hace Alejandro Magno con relación a Diógenes) y el parresiastés hiere el honor del interpelado (lo muerde como un perro que cuida y se arriesga) para que este reconozca que no es lo que dice ser. Foucault (2004a) nos señala que «el juego parresiástico cínico se juega en los límites últimos del contrato parresiástico.» (p. 166). Vale destacar que lo que siempre está en cuestión en el juego parresiástico de modo general, pero que en el caso cínico adquiere un elevado grado de dramaticidad, es la relación con la verdad, particularmente la relación con el coraje de decir y de soportar escuchar la verdad. Ese es el elemento que lleva siempre la relación parresiástica hasta un punto de elevada tensión y la maestría del parresiastés consiste en saber dominar los tiempos oportunos y los modos para llevar al interlocutor hasta la apertura para su propia verdad. El diálogo cínico se parece a una lucha, una batalla, una guerra que mezcla momentos intensos con otros de calma, agresividad y dulzura. A modo de ilustración de lo que estamos diciendo cabe destacar que Diógenes le muestra a Alejandro Magno que él no es lo que cree ser y que si quiere ser rey no lo será por naturaleza o herencia, sino por adoptar un nuevo ethos que es el luchar permanentemente, no contra ejércitos y naciones, sino contra sí mismo como lo hacen los cínicos. La parrhesía cínica tiene como meta llevar al interlocutor a mantener una guerra permanente consigo mismo y el parresiastés representa el lugar del poder de la verdad.

Entendemos, además, que este tipo específico de parrhesía tiene al cuerpo como lugar de irrupción de la verdad. El «decir verdadero» no se limita al logos en cuanto oralidad, sino que lo transforma, el logos no se limita a la palabra, sino que la palabra es indecidible sin la presencia corpórea, por decirlo de algún modo la palabra juega en el cuerpo, o tal vez mejor, «se juega o se hace jugar en el cuerpo», el juego parresiástico cínico dice en y con el cuerpo. En ese registro se hace necesario revisar las fronteras, porque ellas en el cinismo parecen diluirse o entrar en un umbral en el cual se tornan indecidibles. El cuerpo como lugar habitual de la zoé, de la vida biológica, de la naturaleza, irrumpe como lócus en el cual el logos y la palabra se realizan. De ese modo bíos y zoé no se diferencian como un par que opera en la lógica del tercero excluido, o sea, un esquema en el cual el cuerpo, bajo la condición de su disciplinamiento, subordinación y, principalmente, silenciamiento, permite al 
logos, que este se realice, sino que, al contrario es constitutivo del mismo. La performatividad es una marca decisiva del cinismo. El criterio de verdad en esa corriente es la posibilidad de afirmar en el cuerpo la verdad, el cuerpo es condición de verificabilidad y de producción de la verdad. Nos apoyamos en las palabras de Gros (2010, p. 362) para subrayar esta idea: «Ese entrelazamiento tupido de la vida y la verdad, ese empeño en manifestar la verdad en el cuerpo visible de la existencia, constituiría lo esencial del cinismo». Es la vida misma la que emerge como objeto privilegiado de la filosofía y por ende del decir verdadero. En otro momento, el autor amplía esa idea diciendo que:

\footnotetext{
Con los cínicos, la pretensión radica en hacer estallar la verdad en la vida como escándalo. La relación entre verdad y vida es a la vez más estrecha y más polémica. No se busca regular la vida según un discurso, y por ejemplo adoptar un comportamiento justo mientras se defiende la idea misma de justicia, sino hacer directamente legible en el cuerpo la presencia resplandeciente y salvaje de la verdad desnuda, convertir la existencia en el teatro provocador del escándalo de la verdad. (Gros, 2014, p. 137)
}

Es en la vida, en su condición de inmanencia radical por tener al cuerpo como lócus, en donde la verdad es puesta a prueba, y es en el cuerpo en donde la verdad se manifiesta de manera intolerable.

Entendemos que es necesario detenernos un momento en esa idea porque nos parece ser de crucial importancia para el proceso argumentativo que aquí presentamos. Al hacer del cuerpo el principio de verificabilidad de la verdad, al contrario de lo que puede parecer, los cínicos hacen una experiencia (en el sentido estricto de la palabra) de la levedad del ascetismo. En una lectura rápida, levedad y ascetismo parecen ser (por lo menos a los que nos vinculamos a la tradición judeo-cristiana) elementos antitéticos, en la medida en que el ascetismo es asociado a una relación con el cuerpo referenciada en la renuncia a los placeres y un dominio del cuerpo que representa el vencer siempre cada día de nuevo los males que nos asombran, que siempre tienen en lo corpóreo su lugar de anclaje. Por otra parte, el ascetismo cínico muestra el ideal de felicidad con una vida vivida sin las demandas, siempre superfluas, arbitrarias e incesantes que la vida de la pólis (nosotros modernos diríamos la civilización) impone, es un cuerpo que tiene como horizonte, literalmente, descargarse del peso de ese proceso. Por ese motivo, logos, cuerpo y felicidad parecen amalgamarse en el cinismo.

El modo cínico de expresión parresiástico es, como ya mencionamos, una inflexión en dirección a la finitud y a la inmanencia. Entendemos, siguiendo las consideraciones de Gros $(2011,2014)$ que ese desplazamiento puede ser entendido a partir del movimiento del par: "otra vida y otro mundo», que caracteriza al bíos philosophikos, por el otro de «vida otra y mundo otro». En cuanto el primer par está referenciado en la metafísica, la división cuerpo-alma y el alma como esencia humana; el segundo par está situado en la inmanencia y muestra en el cuerpo una vida otra posible, que señala un mundo otro, la posibilidad de contrafáctico, pero no «más allá», sino en el presente. Así, el bíos kynikós es una clara manifestación de una crítica del presente que se realiza en el cuerpo que muestra la verdad como escándalo y que tiene su horizonte en la vida.

Es necesario abordar en este momento el significado de vida escandalosa y el lugar del cuerpo en ella. Escándalo aquí no asume el lugar de algo histriónico que 
ridiculiza de forma humillante al objeto de su crítica. El escándalo debe ser asumido como la forma de mostrar, a partir de la radicalización de los principios que fundan el orden social que se cuestiona, la hipocresía de esa misma orden normativa. Por ese motivo, el cínico no es un eremita que se aleja de la vida de la pólis para cuidar de sí, por entender que la vida en la ciudad no se puede remediar, sino que asume el compromiso de dedicar ( $y$ arriesgar) su vida para operar la crítica de la vida en la pólis, sin embargo en sus márgenes, radicalizando el carácter político o ético-político de la parrhesía. Ese carácter marginal de vivir la vida es un elemento de capital importancia para la comprensión de la parrhesía cínica. El cínico habita en el margen entre la ciudad y el ambiente externo, la naturaleza; al afirmarse en el margen vive la vida sin la necesidad de responder a los compromisos morales que caracterizan al "ciudadano», pero tampoco se confunde con la naturaleza, pero de ella se aproxima hasta el límite mínimo posible. El habitar el margen le permite al cínico ser el espejo roto que le muestra al ciudadano la banalidad y la hipocresía de sus hábitos morales, algo como un espejo anti-narcístico, que tiene al cuerpo como su lugar privilegiado de expresión. Por ese motivo, como decíamos anteriormente, la parrhesía cínica es aquella en la que el componente político es constitutivo.

Para entender ese movimiento debemos recurrir a los principios de la vida cínica. La singularidad de la parrhesía cínica radica en que en ella se aplican los cuatro valores de la verdad: no es disimulada porque se trata de una vida literalmente desnuda que habita el espacio público, se realiza sin mezcla porque tiene solo a sí misma en cuanto pobreza radical, es recta porque está sometida a las leyes de la naturaleza y afirmada en el principio de la animalidad y soberana porque el imperio del cínico es absoluto: es del tamaño de su vida (Gros, 2011, 2014; Foucault, 2010). La vida desnuda significa que no hay nada a esconder y el cuerpo desnudo y sus expresiones (por ejemplo, copular y masturbarse públicamente) no son más que maneras de mostrar que no hay nada a esconder. Que la vida, cuando no es disimulada, nada tiene que restringir al espacio privado, el carácter público de la vida encuentra aquí su expresión más plena. Aquí el pudor de la ciudad y de los ciudadanos es puesto a prueba, porque aquello que ruboriza es, paradójicamente, lo que no podría hacernos sentir vergüenza. En este sentido, debemos destacar que para los cínicos «la vida pública será pues una vida de naturalidad patente y enteramente visible, como una manera de destacar el principio de que la naturaleza jamás puede ser un mal» (Foucault, 2010, p. 267). Evidentemente que ese principio pone en cuestión nuestro modo de vivir moderno, sobre la importante, y podríamos decir necesaria, distinción entre la esfera pública y la esfera privada. Entendemos que el objeto de la vida cínica no es el de una vouyerizacion de la vida privada, sino, por el contrario, mostrar la importancia de vivir abiertamente y la innecesaria distinción entre la opacidad de la vida privada y la supuesta claridad de la vida pública.

El segundo principio, la vida sin mezcla tiene a la pobreza activa como un elemento central. Pobreza activa porque se trata aquí no de aceptar la pobreza como un destino, sino de buscarla para encontrar lo que es absolutamente necesario para vivir, y solamente ello. Una pobreza que no se amolda, sino que es insatisfecha porque siempre busca nuevos límites, y, por fin, una pobreza que se realiza como actividad voluntaria sobre sí para obtener «coraje, resistencia y tenacidad» (Foucault, 2010, p. 271). Recuperamos en este momento lo que hemos dicho anteriormente sobre el ascetismo, pues aquí se trata de un ascetismo que no es la renuncia y la 
mortificación de lo corpóreo, sino que encuentra en la pobreza que se expresa en lo corpóreo un modo de transformación del ser del sujeto en dirección a la felicidad. Se trata de un ir en dirección a la pobreza como modo de aproximarse, tanto cuanto sea posible, de vivir con aquello que es necesario para estar en conformidad con lo que la naturaleza demanda, entendiendo todo lo demás como superfluo, como una carga innecesaria que obstaculiza una vida libre y que tiene a la felicidad como su horizonte. Encontramos un paralelo con esa idea en el concepto de uso del cuerpo presente en las órdenes mendicantes del catolicismo de la alta Edad Media, particularmente en los franciscanos (Agamben, 2013). Una imagen-idea de ese principio se observa en la alegría que alcanza Diógenes cuando descubre la posibilidad de no comer con un plato y lo arroja lejos de él y pasa, a partir de ese momento en adelante, a alimentarse solamente con el uso de sus manos. La felicidad se halla en la pobreza buscada como una forma de cuidar de sí, que, como dijimos, presupone un transformarse y dar forma a sí mismo.

En tercer lugar, la vida recta porque está sometida a las leyes de la naturaleza. En este principio se afirma la animalidad y tiene como su figura emblemática a Diógenes, el que quiere vivir como un perro. En las siguientes palabras tenemos una cabal comprensión del significado de la reducción a la animalidad: «Habida cuenta que la necesidad es una debilidad, una dependencia, una falta de libertad, el hombre no debe tener otras necesidades que las del animal, las necesidades satisfechas por la naturaleza misma» (Foucault, 2010, p. 279). Nos detendremos un momento en este punto para evitar equívocos interpretativos. Querer vivir en conformidad con la naturaleza no puede ser entendido como un ideal que tiene como horizonte un abandono de la condición humana y un retorno al animal. Nos explicamos. Diógenes (y los cínicos) no quieren ser animales, sino vivir como si fueran animales. Ese «como si» implica una búsqueda de la subjetividad para la producción de la existencia con los mínimos elementos necesarios. Podríamos enunciar esa condición como siendo el paradójico intento de producción de una cultura que tiene como clivaje la crítica a la cultura vigente a partir de la adecuación al orden de la naturaleza.

Por último, pero no menos importante, el imperio absoluto del cínico. El cínico es un rey que lo será siempre (y será mayor que cualquier monarca) porque lo es por naturaleza. El rey cínico es absoluto porque no lucha contra enemigos exteriores, a las tropas de las naciones con la que se confronta, sino que su oponente es interno, son sus vicios y defectos. A ellos, se opone y los domina. Su reinado tiene los límites de su existencia y por ello es un rey ignorado (y que busca ser ignorado), y tiene tres características: 1) la abnegación que lo lleva a la renuncia de sí para ocuparse de los otros; 2) la atención a la gente, una relación médica, de cuidado, intervención y cura; y 3) su carácter belicoso, que caracteriza a quien aplica una medicación dura, que presupone el ataque y el combate. El reinado cínico se alcanza después de una larga y ardua batalla, que solamente comienza cuando se perciben los reales enemigos que no son externos, ya sean adversarios políticos o reinados enemigos u otras fuerzas, sino que la batalla cínica comienza con la percepción de que el reinado solamente se conquista a partir del dominio de sí, que se alcanza por una lucha constante con los propios vicios y pasiones. El rey cínico, al ser aquel que dedica su existencia al cuidado de los otros, y lo hace de manera incisiva y belicosa, 
es siempre un formador, alguien que le muestra al otro, en ocasiones hasta de forma violenta, que debe iniciar una lucha consigo mismo para poder reinar sobre sí.

\section{Consideraciones finales: implicaciones para la educación y la educación corporal}

De lo que hemos expuesto apuntamos que la parrhesía en el modo en que Michel Foucault la analizó, nos permite vislumbrar potentes elementos para pensar la formación humana, dado que ella presupone un elemento central que en nuestra tardía modernidad es un aspecto frágil en el modo en que se realiza tal proceso, a saber: la implicación ética con la verdad enunciada y el coraje del sujeto que orienta el proceso formativo en proferir y profesar tal verdad y la disposición ética de quien escucha para recibir, apropiarse y moldar la propia vida a partir de la verdad, que pasa, a partir de un trabajo artesanal de sí sobre sí mismo, a constituirlo. La producción de la propia vida como una estilística de la existencia o como una obra de arte, puede ser un fértil horizonte en tiempos de producción de la vida en serie. En particular, la parrhesía cínica nos aproxima a una visión radical del lugar del cuerpo en la producción del logos, y en la comprensión de la vida en su carácter contingencial y finito, $y$, así entendemos, que puede ser un terreno fértil para pensar la formación humana. La formación humana contemporánea se debate entre la importancia del saber académico y su (imposible) relación con la ética, mientras el cuerpo parece ser un elemento descuidado por las pedagogías contemporáneas. Entendemos que la recuperación hecha por Michel Foucault de la antigüedad greco-latina no significa una apuesta que nos indique lo que debemos hacer, ni una necesaria e idealizada vuelta atrás en el tiempo, sino que nos permite abrir interrogantes cruciales para problematizar la educación y la educación corporal en la contemporaneidad, nos mueve a pensar en nuevos modos de hacer que interroguen a las tradiciones consagradas y nos desafíen a situar la implicación entre cuerpo, palabra-logos y verdad como un horizonte potente para pensar en el presente una educación y una educación corporal otras a partir de una vida, una palabra, una verdad y un cuerpo otros.

\section{Referencias}

Agamben, G. (2013) Altísima pobreza: reglas monásticas y forma de vida. Buenos Aires, Adriana Hidalgo.

Butler, J. (2008) «¿Qué es la crítica? Un ensayo sobre la virtud de Foucault» en Espósito, M. et al. (Comp.) Producción cultural y prácticas instituyentes. Líneas de ruptura en la crítica institucional. Madrid, Editorial Traficantes de Sueños, Colección Mapas, pp. 141-167.

Deleuze, G. (1995) Conversaciones (1972-1990). Valencia, Pre-textos.

Foucault, M. (1995) «¿Qué es la crítica?». Daimon: Revista de filosofía, Universidad de Murcia, núm. 11, pp. 5-25.

Foucault, M. (2002a) Vigilar y castigar: nacimiento de la prisión. Buenos Aires, Siglo veintiuno Editores.

Foucault, M. (2002b) Historia de la Sexualidad, 1. La voluntad del saber. Buenos Aires, Siglo veintiuno Editores.

Foucault, M. (2003) Historia de la Sexualidad. 2. El uso de los placeres. Buenos Aires, Siglo veintiuno Editores. 
Foucault, M. (2003b) Historia de la Sexualidad. 3. La inquietud de sí. Buenos Aires, Siglo veintiuno Editores.

Foucault, M. (2004a) Discurso y verdad en la Grecia antigua. Buenos Aires, Paidós.

Foucault, M. (2004b) «A ética do cuidado de si como prática da liberdade» en Foucault, M. Ditos \& Escritos V - Ética, Sexualidade, Política. Rio de Janeiro, Forense Universitária, pp. 258-280.

Foucault, M. (2006) La hermenéutica del sujeto. Buenos Aires, Fondo de Cultura Económica.

Foucault, M. (2010) El coraje de la verdad. Curso en el Collège de France (1983-1984). Buenos Aires, Fondo de Cultura Económica.

Foucault, M. (2011) Seguridad, Territorio, Población. Curso en el Collège de France (1977- 1978). Buenos Aires, Fondo de Cultura Económica.

Foucault, M. (2016) Subjetividade e verdade. Curso no Collège de France (1980-1981). San Pablo, Martins Fontes.

Gabilondo, A.; Mejías, F. F. (2004) «Introducción al curso de Berkeley» en Foucault, M., Discurso y verdad en la Grecia antigua. Buenos Aires, Paidós, pp. 11-33.

Gros, F. (2010) «Situación el curso» en Foucault, M. El coraje de la verdad - Curso en el Collège de France (1983-1984). Buenos Aires, Fondo de Cultura Económica, pp. 351-366.

Gros, F. (2011) «Foucault et la vérité cynique». Revista de Filosofía Aurora, Curitba, UFPR, v. 23, n. 32, pp. 53-66.

Gros, F. (2014) «La parresía en Foucault (1982-1984)» en Gros, F. (Ed.) Foucault - el coraje de la verdad. Madrid, Arena Libros, pp. 131-140.

Ortega, F. (2008) O corpo incerto - corporeidade, tecnologias médicas e cultura contemporânea. Rio de Janeiro, Garamond.

Senellart, M. (2011) «Situación del Curso» en Foucault, M., Seguridad, Territorio, Población. Curso en el Collège de France (1977- 1978). Buenos Aires, Fondo de Cultura Económica, pp. 417-453. 
Cos, vida, subjectivitat i veritat: parrhesía i bios en el cinisme. Implicacions per a l'educació i l'educació corporal

Resum: Aquest article tracta sobre el problema del parell conceptual parrhesía-bíos, central en l'últim domini de l'obra de Michel Foucault. S'atura, en particular, en la forma d'elaboració d'aquell parell conceptual en la interpretació del cinisme feta pel pensador francès. En aquell context, es pregunta pel lloc del cos en la producció del logos, i els desplaçaments en la relació entre el cos i la paraula, entre el bíos philosophikós i el bíos kynikós. Problematitza, d'acord amb aquelles elaboracions, possibles implicacions per pensar l'educació i l'educació corporal.

Paraules clau: Michel Foucault, cos, cínics, bíos kynikós, parrhesía cínica.

Corps, vie, subjectivité et vérité: parrhesia et bios dans le cynisme. Implications pour l'éducation et l'éducation corporelle

Résumé: Cet article examine le problème du couple conceptuel parrhesía-bíos, qui est fondamental dans le dernier domaine du travail de Michel Foucault. II s'arrête, en particulier, dans le mode d'élaboration de ce couple conceptuel dans l'interprétation du cynisme faite par le penseur gaulois. Dans ce contexte, il s'interroge sur la place du corps dans la production du logos, et les déplacements dans la relation entre le corps et la parole, entre le bios philosophikós et les bios kynikós. II problématise, sur la base de ces élaborations, des implications possibles pour la réflexion sur l'éducation et l'éducation corporelle.

Mots clés: Michel Foucault, corps, cynique, bíos kynikós, parrhesía cynique.

\section{Body, life, subjectivity and truth: parrhesia and bios in cynicism and implica- tions for education and the education of the body}

Abstract: This article addresses the problem of the conceptual bond between parrhesia and bios that is central to the last area of Michel Foucault's work, focusing on how the two notions are paired in Foucault's interpretation of cynicism. It examines the place of the body in the production of logos and displacement in the relationship between body and word, between bios philosophikos and bios kynikos, in order to frame questions about the implications of Foucauldian thought for our understanding of the education of the body and education in general.

Keywords: Michel Foucault, body, cynics, bios kynikos, cynical parrhesia. 